\title{
Linear mixture model applied to Amazonian vegetation classification
}

\author{
Dengsheng Lu ${ }^{\mathrm{a}, *}$, Emilio Moran ${ }^{\mathrm{a}, \mathrm{b}}$, Mateus Batistella ${ }^{\mathrm{b}, \mathrm{c}}$ \\ ${ }^{a}$ Center for the Study of Institutions, Population, and Environmental Change (CIPEC) Indiana University, 408 N. Indiana Ave., Bloomington, IN, 47408, USA \\ ${ }^{\mathrm{b}}$ Anthropological Center for Training and Research on Global Environmental Change (ACT), Indiana University, Bloomington, IN, USA \\ ${ }^{\mathrm{c}}$ Brazilian Agricultural Research Corporation, EMBRAPA Satellite Monitoring Campinas, São Paulo, Brazil
}

Received 7 September 2001; received in revised form 11 June 2002; accepted 11 June 2002

\begin{abstract}
Many research projects require accurate delineation of different secondary succession (SS) stages over large regions/subregions of the Amazon basin. However, the complexity of vegetation stand structure, abundant vegetation species, and the smooth transition between different SS stages make vegetation classification difficult when using traditional approaches such as the maximum likelihood classifier (MLC). Most of the time, classification distinguishes only between forest/non-forest. It has been difficult to accurately distinguish stages of SS. In this paper, a linear mixture model (LMM) approach is applied to classify successional and mature forests using Thematic Mapper (TM) imagery in the Rondônia region of the Brazilian Amazon. Three endmembers (i.e., shade, soil, and green vegetation or GV) were identified based on the image itself and a constrained least-squares solution was used to unmix the image. This study indicates that the LMM approach is a promising method for distinguishing successional and mature forests in the Amazon basin using TM data. It improved vegetation classification accuracy over that of the MLC. Initial, intermediate, and advanced successional and mature forests were classified with overall accuracy of $78.2 \%$ using a threshold method on the ratio of shade to GV fractions, a 7.4\% increase over the MLC. The GV and shade fractions are sensitive to the change of vegetation stand structures and better capture biophysical structure information.

(C) 2003 Elsevier Inc. All rights reserved.
\end{abstract}

Keywords: Linear mixture model; Secondary succession; Classification; Amazon; Thematic Mapper image

\section{Introduction}

The authors are engaged in a project on Amazon Forest Regeneration and Landscape Structure that is part of the Large-Scale Biosphere-Atmosphere Experiment in Amazônia (LBA). Several of the major research foci of LBA require an accurate delineation of different secondary succession (SS) stages over large regions/subregions of the Amazon basin. Due to their rapid growth and increasing areal extent, successional forests play an important role in the global carbon budget. Moreover, they have significant ecological functions within Amazonian ecosystems and landscapes affecting soil fertility, vegetation structure and composition, and faunal dispersion. The research focusing on successional forests has attracted increasing attention (Alves et al., 1997; Guariguata \& Ostertag, 2001; Kimes, Nelson, Salas, \& Skole, 1999; Kimes, Nelson, Skole, \& 2634.

* Corresponding author. Tel.: +1-812-855-2230; fax: +1-812-855-

E-mail address: dlu@indiana.edu (D. Lu).
Salas, 1999; Lu, 2001; Lu, Mausel, Brondízio, \& Moran, 2002b; Lucas et al., 1998; Lucas et al., 2000; Lucas, Honzák, do Amaral, Curran, \& Foody, 2002; Lucas, Honzák, Foody, Curran, \& Corves, 1993; Mausel, Wu, Li, Moran, \& Brondízio, 1993; Moran, Brondízio, \& Mausel, 1994; Moran et al., 2000; Nelson, Kimes, Salas, \& Routhier, 2000; Nelson et al., 1999). Previous studies by our research group successfully classified multiple stages of vegetation regrowth in Amazônia (Brondízio, Moran, Mausel,\& Wu, 1994; Li, Moran, Brondízio, Mausel, \& Wu, 1994; Mausel et al., 1993; Moran, Brondízio, Mausel, \& Wu, 1994). During these efforts we have steadily improved accuracy of SS classification through the integration of intensive field data collection and remote sensing analyses.

The difficulty of accurately classifying stages of SS can be related to many factors. The heterogeneity of the vegetation structure is a major problem, as is the limitation of spatial resolution, i.e., where a single Landsat TM pixel often contains more than one land-cover class. Even within the same vegetation class there is often great variation in plant species, plant geometry, vegetation structure and 
biomass. The complexity of vegetation stand structure, the abundance of species, and the smooth transition between different SS stages make digital classification difficult when using traditional approaches, such as the maximum likelihood classifier (MLC).

Traditional classifiers typically develop a signature by combining the spectra of all pixels within a training set from a given feature. The resulting signature contains the contributions of all materials present in the training set (Huguenin, Karaska, Blaricom, \& Jensen, 1997). Therefore, traditional classifiers cannot effectively handle the mixedpixel problem. In order to reduce mixed-pixel effects, a variety of methods have been developed to unmix the pixels into different proportions of the endmembers (Atkinson, Cutler, \& Lewts, 1997; Bastin, 1997; Erol, 2000; Ichoku \& Karnieli, 1996).

The linear mixture model (LMM) approach is one of the most often used methods for handling the mixed pixel problem. It evaluates each pixel spectrum as a linear combination of a set of endmember spectra (Adams et al., 1995; Roberts, Batista, Pereira, Waller, \& Nelson, 1998). The endmember spectra are selected to be as different as possible from one another. The output is typically presented in the form of fraction images for each endmember spectrum, which gives the derived fractions of each endmember spectrum for each pixel. A residual image provides the rootmean-square (RMS) of the fit for each pixel (Huguenin et al., 1997). In remote sensing data applications, the LMM approach has been used to

1. classify vegetation and land-use/land-cover (LULC) classes (Aguiar, Shimabukuro, \& Mascarenhas, 1999; Cochrane \& Souza, 1998; DeFries, Hansen, \& Townshend, 2000; Theseira, Thomas, \& Sannier, 2002; Ustin, Hart, Duan, \& Scheer, 1996; Ustin, Smith, Jacquemoud, Verstraete, \& Govaerts, 1999);

2. detect LULC changes (Adams et al., 1995; Elmore, Mustard, Manning, \& Lobell, 2000; Roberts et al., 1998; Roberts, Green, \& Adams, 1997; Roberts et al., 2002; Rogan, Franklin, \& Roberts, 2002; Shimabukuro, Batista, Melio, Moreira, \& Duarte, 1998; Ustin, Roberts, \& Hart, 1998);

3. measure sparse vegetation cover (Asner \&Lobell, 2000; McGwire, Minor, \& Fenstermaker, 2000; Smith, Ustin, Adams, \& Gillespie, 1990; Sohn \& McCoy, 1997) and crop area (Maas, 2000; Quarmby, Townshend, Settle, \& White, 1992);

4. map floodplain habitats (Novo \& Shimabukuro, 1997);

5. determine urban vegetation abundance (Small, 2001); and

6. estimate biophysical parameters such as abundance in heterogeneous canopies (Gilabert, Garcia-Haro, \& Melia, 2000), leaf area index, biomass, and net primary productivity (Garcia-Haro, Gilabert, \& Melia, 1996; Hall, Shimabukuro, \& Huemmrich, 1995; Peddle, Hall, \& LeDrew, 1999; Peddle, Brunke, \& Hall, 2001).
This article focuses on the application of LMM to classify successional and mature forests in the Brazilian Amazon with less dependence on intensive field data collection as the means to achieve acceptable accuracy.

\section{Brief characteristics of tropical successional forests}

Amazon colonization has produced widespread deforestation but also a mosaic of secondary successional vegetation. Distinct regeneration patterns are affected by land-use history and the various land management practices following deforestation. Different SS stages have different stand structures, species compositions, and biomass. Although it is difficult to define regrowth classes in the Amazon, the use of vegetation structure data and remote sensing techniques improves the capability of distinguishing them. These initiatives comply with the need to monitor LULC in the region based on the rationale that secondary vegetation will not preserve the total biodiversity of mature forests, but it plays an important role in the Amazonian forest's structure and function (Smith et al., 1997).

Pioneer species such as light-demanding herbaceous plants, grasses, vines, seedlings, and saplings dominate in the initial secondary succession (SS1) stage. These species have a short life cycle, high growth rate, and high reproductive resource allocation (Gómez-Pompa \& VásquezYanes, 1981). Some tree species become important after the second or third year of regrowth. Besides palms, species commonly associated with this period include Vismia sp. and Cecropia sp. The density of saplings is higher than the density of trees, indicating their importance within the structural characteristics of SS1.

In intermediate secondary succession (SS2) stage, vegetation structure results from a mix of dense ground cover of saplings and young trees with higher canopy than SS1 and very small internal difference between canopy and understory individuals. Young trees are already present but saplings still have a higher density. A more closed canopy alters the microclimate, improving conditions for shadetolerant tree species and creating an unsuitable environment for pioneer species. This profound change sets the path to a more advanced stage of vegetation regrowth.

In advanced secondary succession (SS3), trees occupy the canopy and vegetation structure presents obvious stratification. Although large Cecropia are still present, most pioneer species give way to slow-growing, shadetolerant forest species. The general appearance of this vegetation type in terms of canopy layers is similar to a forest. However, trees are still not as high or thick, as explained below. In SS3, there is a major shift in structure that differentiates understory from canopy individuals; that is, the presence of saplings is less significant than that of trees. One can find differences between the canopy and understory in terms of height and density of individuals at both levels. SS3 presents a less continuous vertical profile 
and a clear distinction between dominant trees and less dense saplings.

In the mature forest, above-ground biomass and vegetation density can be significantly different depending on soil conditions, species composition, and topography at the site. Some mature forests have tree diameter at breast height (DBH), tree height, and above-ground biomass similar to SS3. In a typical mature forest, trees account for the majority of above-ground biomass, often more than $90 \%$. Despite these variations, the vegetation formation comprises relatively widely spaced tree individuals, sometimes including palms, bamboo, and lianas. A more detailed description about the vegetation stand structure of different SS stages and mature forest can be found in Moran and Brondízio (1998), Batistella (2001) and Lu (2001).

\section{Evaluation of SS classification methods}

Different approaches have been used to identify SS stages in previous research. The most straightforward method is based on the vegetation age (Saldarriaga, West, Tharp, \& Uhl, 1988; Uhl, Buschbacher, \& Serrao, 1988). However, vegetation stands can be significantly influenced by landuse history (Uhl et al., 1988), soil fertility (Moran et al., 2000 ), original vegetation, and clearing size (Tucker, Brondízio, \& Moran, 1998). Age alone cannot be used to predict SS stages since many factors can strongly affect structural characteristics within the same age class. Moran and Brondízio (1998) defined regrowth stages of Amazonian tropical forest based on the analysis of average stand height and basal area. They found that stand height was a significant discriminator for SS1, SS2 and SS3. Tucker et al. (1998) analyzed physiognomic characteristics in two different Amazonian sites to classify SS stages and found that the central discriminating factor between stages of succession was the contribution of saplings and trees to the fallow's total basal area. Sapling/tree basal area relations can help predict other structural features and effectively differentiate SS stages in the field. Lu (2001) used canonical discriminant analysis (CDA) to identify different SS stages and mature forest in the eastern Amazon based on field measurements. The ratio of tree biomass to total biomass (RTB) was found to be a good biophysical parameter in differentiating SS stages. The vegetation samples were grouped as SS1 when RTB was less than $15 \%$, SS2 when RTB ranged from $16 \%$ to $45 \%$, SS3 when RTB ranged from $46 \%$ to $89 \%$, and mature forest when RTB was greater than $90 \%$. As an alternative, a combination of stand parameters can be used to identify SS stages. Average stand diameter and height are more appropriate in differentiating SS stages, and above-ground biomass and average stand diameter are more suitable for separating mature forest from SS stages (Lu, 2001).

Remotely sensed data have been applied extensively for vegetation and LULC classification. In the Brazilian Amazon, remote-sensing technology has been extensively used to classify LULC or SS and to detect deforestation (Adams et al., 1995; Batistella, 2001; Brondízio, Moran, Mausel, \& Wu, 1996; Brondízio et al., 1994; Foody \& Curran, 1994; Foody, Palubinskas, Lucas, Curran, \& Honzák, 1996; Li et al., 1994; Lu, 2001; Lu et al., 2002b; Lucas et al., 1993; Mausel et al., 1993; McCracken et al., 1999; Moran \& Brondízio, 1998; Moran, Brondízio, \& Mausel, 1994; Moran, Brondízio, Mausel, \& Wu, 1994; Rignot, Salas, \& Skole, 1997; Roberts et al., 1998, 2002; Saatchi, Soares, \& Alves, 1997; Steininger, 1996; Yanasse et al., 1997). Supported by abundant and accurate field measurements from all classes of interest, Mausel et al. (1993) analyzed Landsat TM spectral responses of different SS stages and classified the vegetation into SS1, SS2, SS3, and mature forest using an extraction and classification of homogeneous objects (ECHO) classifier. Similar studies were conducted by Brondízio et al. (1996), Li et al. (1994) and Moran, Brondízio, and Mausel (1994). However, the classification accuracy greatly depends on the availability and quality of a very large number of training data sets. Confusion often occurs between degraded pasture and SS1, between different SS stages, and between advanced SS and mature forests, since there is no clear distinction between these vegetation classes. For example, the canopy structure of SS3 and mature forest can be very similar although they have significantly different ages and above-ground biomass. The LMM approach is regarded as a physically based image analysis tool. It supports repeatable and accurate extraction of quantitative subpixel information (Roberts et al., 1998; Smith et al., 1990). The fraction images indicate physical characteristics. Therefore, LMM has the potential to provide a better classification of successional and mature forests.

\section{Linear mixture model}

The LMM approach assumes that the spectrum measured by a sensor is a linear combination of the spectra of all components within the pixel (Adams et al., 1995; Roberts et al., 1998; Ustin et al., 1998). The mathematic model of LMM can be expressed as

$R_{i}=\sum_{k=1}^{n} f_{k} R_{i k}+\varepsilon_{i}$,

where $i=1, \ldots, m$ (number of spectral bands); $k=1, \ldots, n$ (number of endmembers); $R_{i}$ is the spectral reflectance of band $i$ of a pixel, which contains one or more endmembers; $f_{k}$ is the proportion of endmember $k$ within the pixel; $R_{i k}$ is known as the spectral reflectance of endmember $k$ within the pixel on band $i$, and $\varepsilon_{i}$ is the error for band $i$. For a constrained unmixture solution, $f_{k}$ is subject to the following restrictions:

$\sum_{k=1}^{n} f_{k}=1$ and $0 \leq f_{k} \leq 1$ 
The RMS error was used to assess the fit of the model. The RMS was computed using

$\mathrm{RMS}=\sqrt{\left(\sum_{i=1}^{m} \varepsilon_{i}^{2}\right) / m .}$

The RMS error is calculated for all image pixels. The larger the RMS error, the worse the fit of the model (Mather, 1999). So, the error image can be used to assess whether the endmembers are properly selected and whether the number of selected endmembers is sufficient.

The high quality of fraction images greatly depends on proper selection of endmembers and sufficient number of endmembers. A variety of methods were used to determine endmembers. For example, the endmembers can be obtained from (1) a spectral library, if available, such as provided by ERDAS IMAGINE and ENVI software packages; (2) laboratory or field reflectance measurements; (3) the image itself (Quarmby et al., 1992; Settle \& Drake, 1993) or high-order principal component analysis (PCA) eigenvectors (Boardman, 1993); (4) spectrally pure pixels that are identified using the Pixel Purity Index (PPI) (Boardman, Kruse, \& Green, 1995), which are selected manually by visualizing the PPI results in an $N$-dimensional visualizer with ENVI (RSI, 2000); (5) using manual endmember selection (Bateson \& Curtiss, 1996), a multidimensional visualization technique for interactively exploring the mixing space in search of spectra to designate as endmembers; and (6) the combination of image and reference endmember selection methods, including a spectral alignment of the image endmembers to the reference endmember spectra, and a calibration relating the image endmembers to the reference endmembers (Roberts, Smith, \& Adams, 1993; Smith et al., 1990). Some previous literature has discussed and summarized the methods for endmember selection (Adams, Smith, \& Gillespie, 1993; Mustard \& Sunshine, 1999; Tompkins, Mustard, Pieters, \& Forsyth, 1997). For many applications of LMM, image endmembers are used because they can be obtained easily, representing spectra measured at the same scale as the image data (Roberts et al., 1998). The endmembers are regarded as the extremes of the triangles of an image scattergram. For example, the green vegetation (GV) endmember has high reflectance in TM 4 and low reflectance in TM 3, the soil endmember has high reflectance in TM 3 and TM 4, and the shadow endmember has very low reflectance in TM 3 and TM 4. It is important to consider spatial scale and to avoid outliers when endmembers are determined from the image itself.

The method to define the number and types of endmembers varies with specific applications but includes statistical procedures (e.g., factor analysis) to identify the intrinsic dimensionality of the data, or specification of materials of known interest (Ustin, Smith, \& Adams, 1993). A common approach for determining the number of endmembers is to find the PCA eigenvectors or directions accounting for most of the variance in the data (Ichoku \& Karnieli, 1996). Typically, three to seven endmembers are appropriate for most applications, depending on the number of channels used and the spectral variability of the scene components (Mustard \& Sunshine, 1999). Ustin et al. (1996) indicated that regardless of the number of bands, only two to six endmembers were needed to characterize the overall variance in the image to the noise level. For example, three endmembers (e.g., $\mathrm{GV}$, shade and soil) or four endmembers (e.g., GV, shade, soil and non-photosynthetic vegetation or NPV) are often used on the TM image (Adams et al., 1995; Aguiar et al., 1999; Cochrane \& Souza, 1998; Smith et al., 1990; Shimabukuro \& Smith, 1995; Roberts et al., 1998, 2002; Ustin et al., 1998).

\section{Study area and field data collection}

Rondônia has experienced high deforestation rates during the last decade. The deforestation rates in Rondônia range from $1.14 \%$ to $2.62 \%$ per year between 1991 and 2000 , much higher than the overall deforestation rate (ranging from 0.37 to $0.80 \%$ per year) in the Brazilian Amazon basin at the same period (INPE, 2002). Following the national strategy of regional occupation and development, colonization projects initiated by the Brazilian government in the 1970s played a major role in this process (Moran, 1981; Schmink \& Wood, 1992). Most colonization projects in the state were designed to settle landless migrants. Batistella et al. have compared distinct settlement strategies implemented in the early 1980s (Batistella, Brondízio, \& Moran, 2000; Batistella \& de Castro, 2001), calling attention to the need for multitemporal LULC assessments to understand the history of occupation and the trends for the future. The accurate classification of vegetation types responds to this demand. The data used in this study were collected in Machadinho d'Oeste in northeastern Rondônia (Fig. 1). Settlement began in this area in the mid-1980s, and the immigrants transformed the forested landscape into a patchwork of cultivated crops, pastures, and a vast area of fallow land. The climate in Machadinho d'Oeste is classified as equatorial hot and humid, with tropical transition. The well-defined dry season lasts from June to August, and the annual average precipitation is 2016 mm (Rondônia, 1998). The annual average temperature is $25.5{ }^{\circ} \mathrm{C}$ and monthly relative humidity averages between $80 \%$ and $85 \%$. These characteristics make the monthly potential evapotranspiration very constant, and the real and potential evapotranspiration are coincident with exception for the dry months (Shuttleworth, 1998). The terrain is undulated, ranging from 100 to $450 \mathrm{~m}$ above sea level. Several soil types, such as alfisols, oxisols, ultisols, alluvial soils, and other less spatially represented associations, were identified (Miranda \& Mattos, 1993). Settlers, 


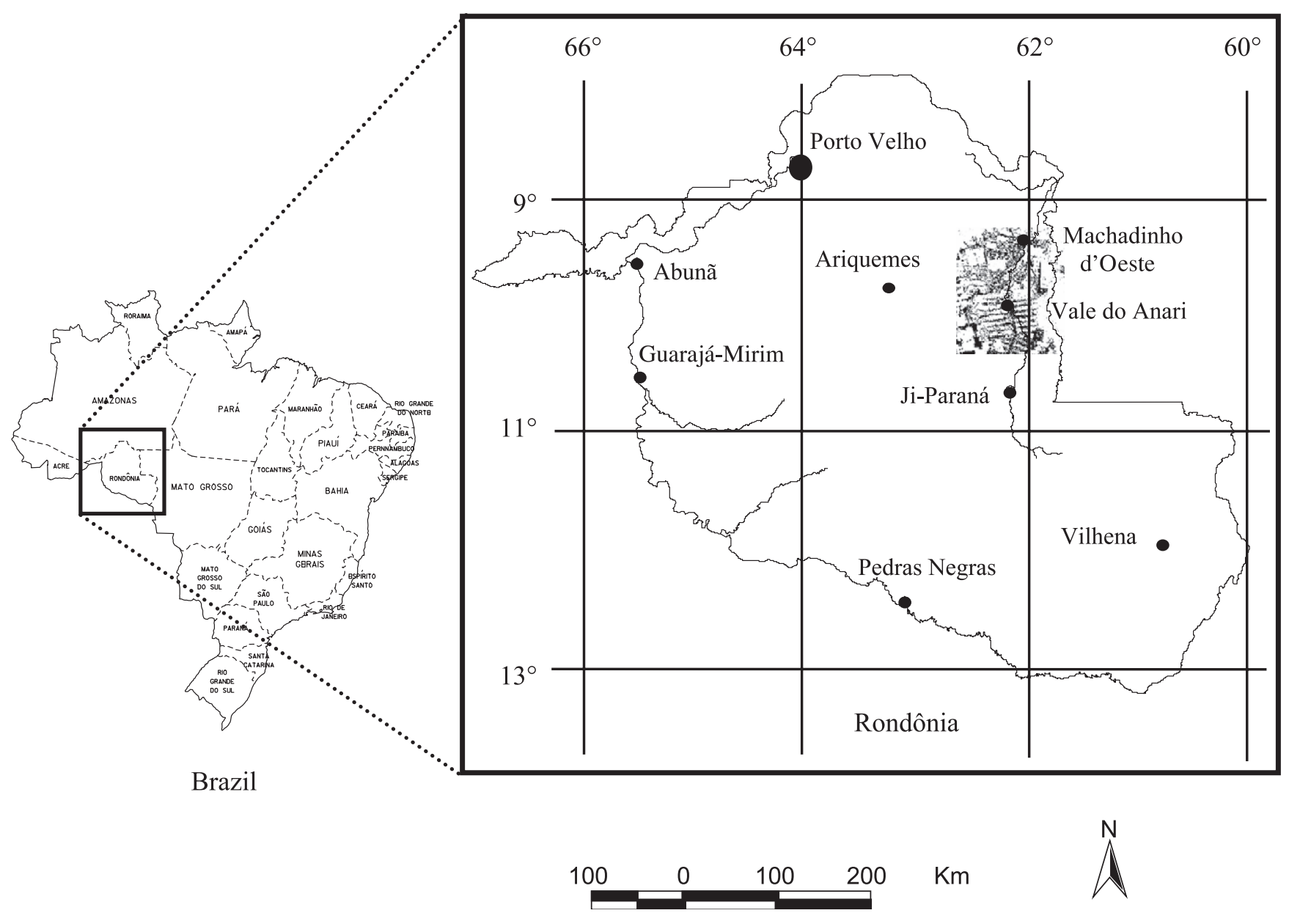

Fig. 1. Location of Machadinho d'Oeste in the state of Rondônia.

rubber tappers, and loggers inhabit the area, transforming the landscape through their economic activities and use of resources.

Fieldwork was carried out during the dry seasons of 1999 and 2000. Preliminary image classification and band composite printouts indicated candidate areas to be surveyed, and a flight over the areas provided visual insights about the size, condition, and accessibility of each site. After driving extensively throughout the settlements, field observations gave a sense about the structure of regrowth stages, mainly regarding total height and ground cover of dominant species. Indicator species, such as Cecropia sp., Vismia sp., palms, grassy vegetation, and lianas also helped to assign the SS stages. The procedure used for surveying vegetation was a multilevel technique adapted from methods used by researchers at the Center for the Study of Institutions, Population, and Environmental Change (CIPEC) (CIPEC, 1998). After defining the area to be surveyed (plot sample), three subplots were randomly installed to cover the variability within the plot sample. A subplot is composed of three nested squares: one for sampling ground cover and tree or woody climber species seedlings $\left(1 \mathrm{~m}^{2}\right)$; one for sampling sapling information $(9$ $\left.\mathrm{m}^{2}\right)$; and one for sampling trees and woody species $(100$ $\mathrm{m}^{2}$ ). The center of each subplot was randomly selected. Seedlings were defined as young trees or shrubs with a maximum stem diameter less than $2.5 \mathrm{~cm}$. Saplings were defined as young trees with DBH from $2.5 \mathrm{~cm}$ to less than $10 \mathrm{~cm}$. Trees were defined as woody plants with a DBH greater than or equal to $10 \mathrm{~cm}$. Height, stem height, and DBH were measured for all trees in the $100 \mathrm{~m}^{2}$ area. Height and DBH were measured for all saplings in the 9 $\mathrm{m}^{2}$ area. Ground cover estimation and counting of individuals were carried out for seedlings and herbaceous vegetation in the $1 \mathrm{~m}^{2}$ area. Every plot was registered with a global positioning system (GPS) device to allow further integration with spatial data in geographic information systems (GIS) and image processing systems. Forty plots and 120 subplots were measured during the fieldwork in 1999 and 2000. Meanwhile, many sites covering different land-cover types were also identified and land-use history was recorded during the fieldwork. Some of the field data were used for classification and some were used for test data. IKONOS data were also used to identify more test sites for classification accuracy assessment. 


\section{Vegetation classification}

Fig. 2 illustrates the framework for vegetation classification using LMM. TM data acquired on June 18, 1998, were radiometrically calibrated and atmospherically corrected into surface reflectance using an improved image-based dark object subtraction (DOS) model (Chavez, 1996; Lu, Mausel, Brondízio, \& Moran, 2002a). The path radiance was identified based on clear water for each band. The atmospheric transmittance values for visible and near infrared bands were derived from Chavez (1996), which were an average for each spectral band derived from radiative transfer code. For middle infrared bands, the atmospheric transmittance was set to one. The image was geometrically rectified based on control points taken from topographic maps at 1:100,000 scale (UTM south 20 zone). Nearestneighbor resampling technique was used. The RMS error was smaller than 0.5 pixel.

Image endmembers were derived from the extremes of the image feature space, assuming they represent the purest pixels in the images (Mustard \& Sunshine, 1999). Three endmembers (shade, soil and GV) were identified from the scattergram of TM 3 and TM 4 and the scattergram of TM 4 and TM 5. An average of 4-10 pixels of these vertices was calculated. When selecting the endmembers, caution must be taken to identify outliers. Appropriate selection of image endmembers is very important and is often an iterative

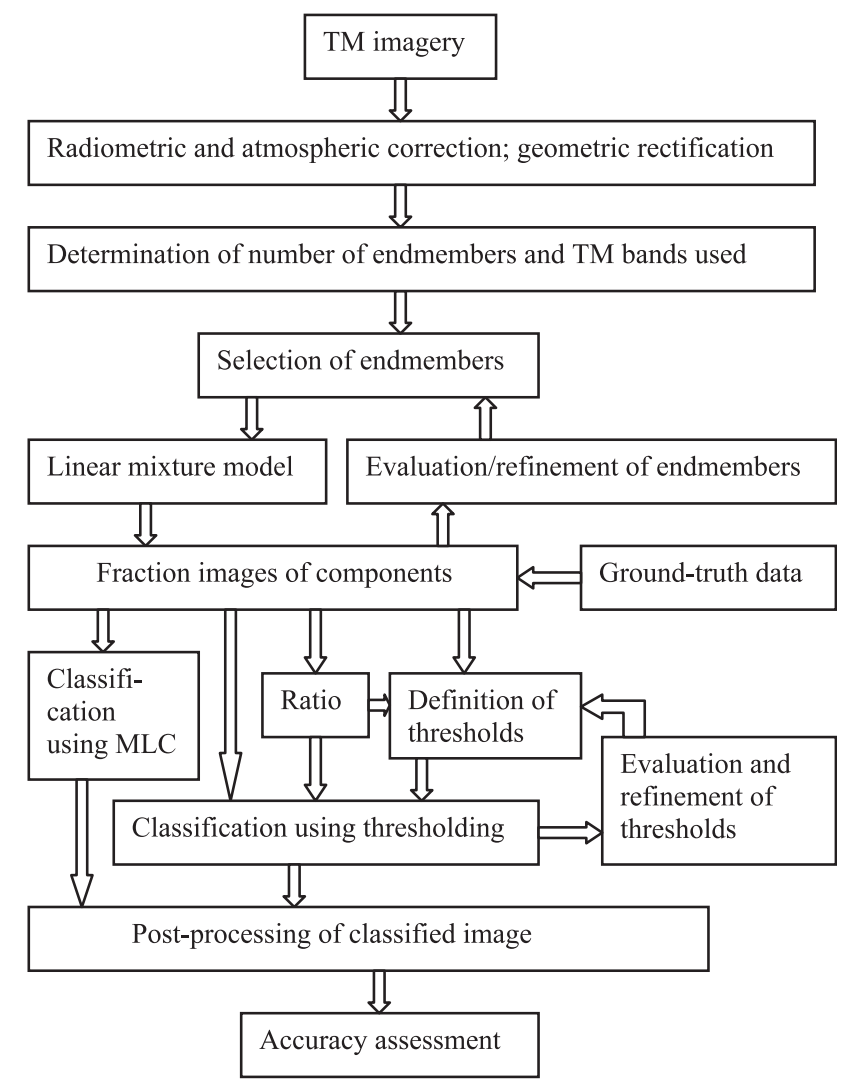

Fig. 2. Framework of LMM application to vegetation classification. process. The RMS error image was one of the indicators to assess whether the selected endmembers were appropriate or not. A constrained least-square solution was used to unmix the mixture model.

Different SS stages have different shade and GV fractions, in which the majority of vegetation information is concentrated. The ratio of shade to GV has the potential to improve the separability between SS stages. The soil fraction contains less vegetation information and was not useful in the SS classification. After the fractions were developed, different analysis methods were used: (1) the fractions were used as input for other classifiers such as MLC; (2) definition of threshold for each SS stage based on GV and shade fractions; and (3) definition of thresholds based on the shade-to-GV ratio image. As a comparison, MLC was also conducted on the atmospherically corrected TM image. Because GPS devices provided the coordinates for ground-reference data during fieldwork, the sample plots can be accurately linked to TM imagery or endmember fraction images for classification or determination of threshold ranges for each class. Data from 60 sample plots were used for definition of thresholds for each successional and mature forest class or for training sample sets in MLC. The image value for each sample plot was extracted based on selected polygons, with polygon sizes ranging from 6 to 15 pixels for successional forests and from 15 to 25 pixels for mature forest.

The definition of thresholds is an important factor affecting the final classification results. However, it is not easy to find the optimal thresholds for each class because of the smooth transition between different successional stages and mature forest. It is often an iterative process to find the best threshold. The following steps provide the method used for determining an appropriate threshold for each vegetation class:

1. Define the areas of interest (AOIs) using the ERDAS IMAGINE AOI tool on the endmember fraction images that correspond to known classes of vegetation based on field observations.

2. Report the statistics (e.g., minimum, maximum, mean, and standard deviation) and draw graphs for each vegetation class.

3. Define the thresholds for each class based on the graph and statistics.

4. Classify vegetation classes using the defined thresholds.

5. Assess the classified image through comparison with ground-truth data.

6. Refine the threshold and implement classification again.

Because of the extensive time involved and difficulty in defining the optimum threshold for each SS class, it is necessary to adopt other methods to avoid manually defining thresholds. One way to solve this problem is to use the fraction images as inputs and then to use traditional classifiers to classify the fraction images. In this paper, MLC is used to classify the vegetation classes on the GV and shade fraction images. 
A common method for classification accuracy assessment is through the use of an error matrix. Previous literature has provided the meanings and calculation methods for overall accuracy (OA), producer's accuracy (PA), user's accuracy (UA), and kappa coefficient (Campbell, 1996; Congalton, 1991; Congalton \& Mead, 1983; Congalton, Oderwald, \& Mead, 1983; Janssen \& van der Wel, 1994; Jensen, 1996; Kalkhan, Reich, \& Czaplewski, 1997; Khorram, 1999; Smits, Dellepiane, \& Schowengerdt, 1999). Kappa analysis was recognized as a powerful technique used for analyzing a single error matrix and comparing the difference between different error matrices (Congalton, 1991; Smits et al., 1999). A detailed description about the kappa analysis can be found (Congalton et al., 1983; Congalton, 1991; Hudson \& Ramm, 1987; Kalkhan et al., 1997; Smits et al., 1999). In this paper, an error matrix for each classification method was produced. UA, PA, OA were calculated for each classification method. KHAT statistic, kappa variance, and $Z$ statistic were used to compare the performance among different classification methods.

\section{Results and discussions}

Fig. 3 illustrates reflectance curves of different SS stages and mature forest in the atmospherically corrected TM images. It indicates that mature forest has a low reflectance

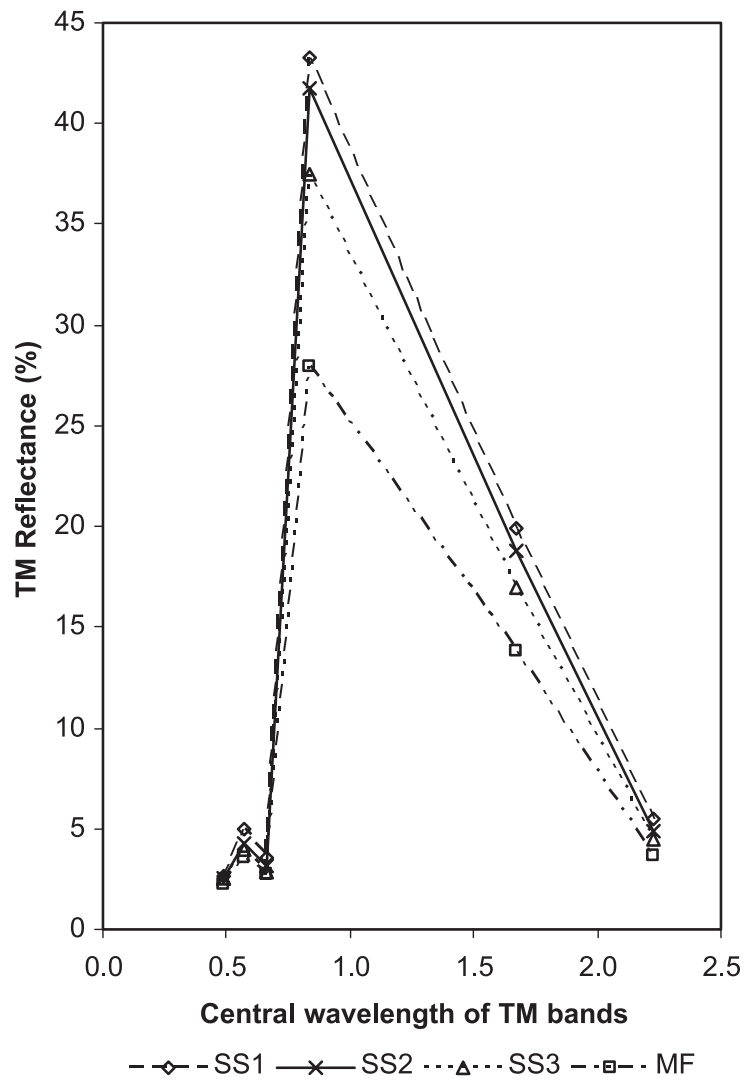

Fig. 3. TM reflectance curves of successional and mature forests.

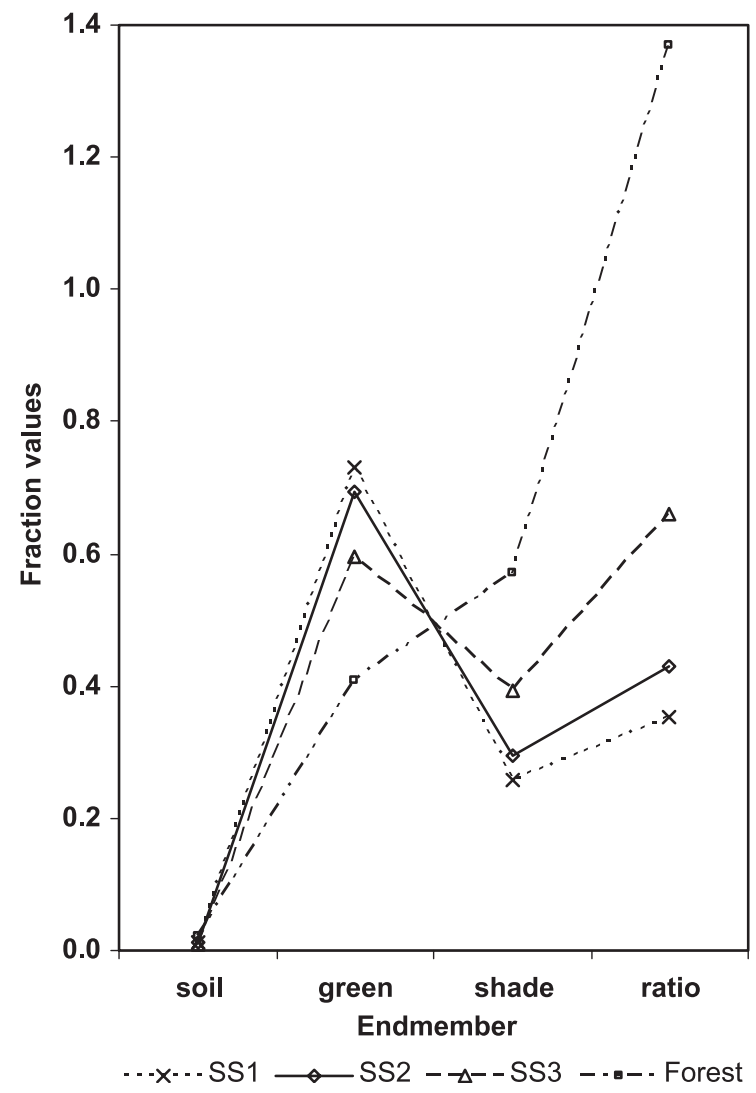

Fig. 4. Comparison of endmember fractions among successional and mature forests.

value in each TM band and a better separability from SS stages, especially in the near infrared band TM 4 and the middle infrared band TM 5. SS1 and SS2 have similar reflectance. This confirms the opinion of many scholars that classification of SS stages based on pure spectral materials is very difficult using per-pixel classifiers such as the MLC.

Fig. 4 provides a comparison between different SS stages and mature forest based on endmember fractions and the ratio of shade to $\mathrm{GV}$ fractions. It shows that the GV fraction decreases as vegetation changes from SS1 to SS3 and to mature forest, but shade fraction increases as vegetation grows. Mature forest has the highest shade fraction and the lowest GV fraction. In contrast, SS1 has the lowest shade fraction and highest GV fraction. Different SS stages and mature forests have very low soil fraction values and cannot be discriminated based on the soil fraction image. The characteristics of different SS stages and mature forest in $\mathrm{GV}$ and shade fraction images provide the potential to better discriminate the vegetation classes. The ratio of shade-to$\mathrm{GV}$ fraction enlarges the separability among mature forest and different SS stages, providing the possibility to further improve the discrimination among different SS stages and mature forest.

Fig. 5 illustrates part of the study area associated with fraction images of soil, shade, and GV endmembers, respectively. Urban, road, and bare soil appear white on the soil 


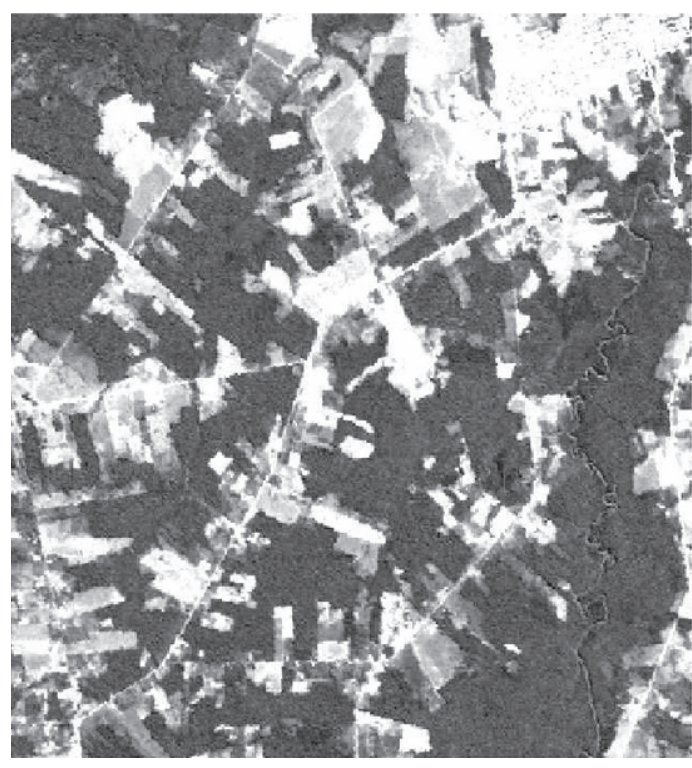

A: Soil fraction

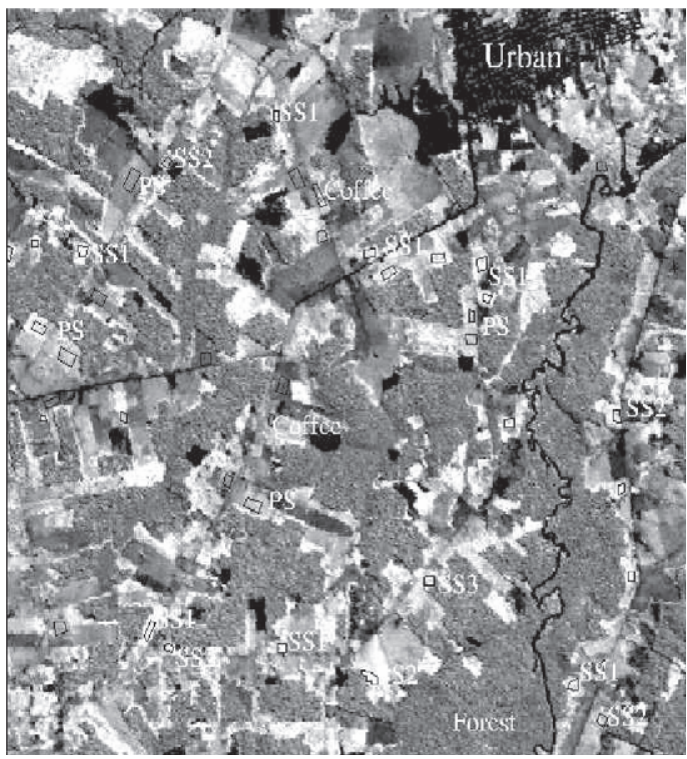

C: GV fraction with sample data

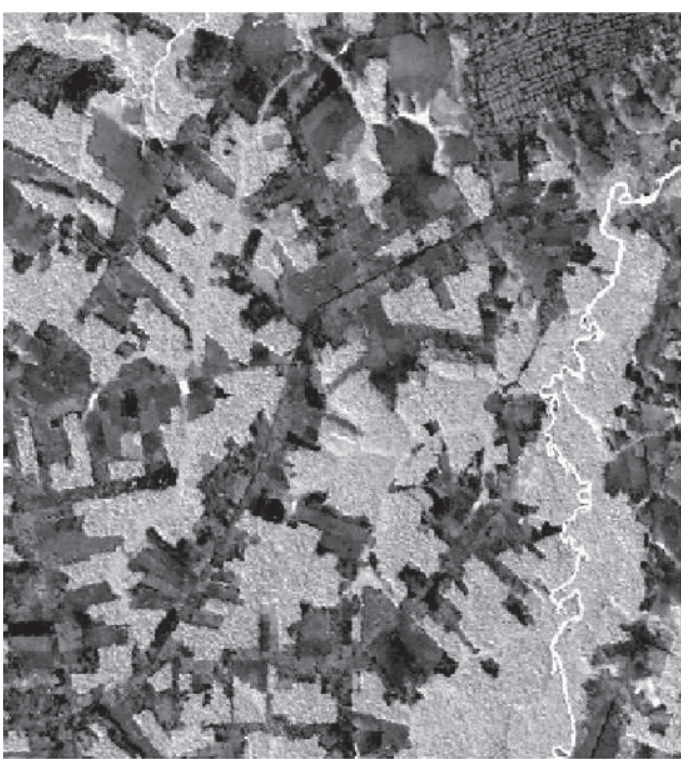

B: Shade fraction

Some typical land covers on the GV fraction:

SS1: Initial SS

SS2: Intermediate SS

SS3: Advanced SS

PS: Pasture

Mature forest

Coffee plantation

Urban

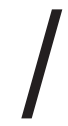

$10 \mathrm{~km}$

Fig. 5. Fraction images of soil, shade, and GV endmembers for part of the study area.

fraction (Fig. 5A) due to their high fraction values. Pasture and agricultural lands appear grey, successional and mature forests, and water appears black due to its very low soil fraction values. In contrast, in the shade fraction image (Fig. 5B), water appears white and mature forests appear brighter grey due to their high shade fraction values. Successional forests, some agricultural land such as coffee plantation and degraded pasture appear grey. Urban areas, roads, and bare soil appear dark grey. On the shade fraction image, mature forest has significant different fraction values compared with other land-cover types. On the GV fraction image (Fig. 5C), successional forests, especially SS1 and SS2, appear white due to their high GV fraction values. Mature forests appear grey. Pasture and agricultural lands had a wide variation in GV fraction. Some of them (e.g., degraded pasture, coffee plantation) had similar GV fractions as successional forests. Water, urban, and bare soils appear black. Fraction differences between the various land-cover types provide the basis for better separation of land-cover classes using the LMM approach. The polygons overlaid on the GV fraction image (Fig. 5C) illustrate the link between field data and image data.

Fig. 6 illustrates the classified image generated using the threshold method on shade-to-GV ratio image. Water was first derived from the shade fraction image. Urban and bare soils, pasture and agricultural lands were classified from the 

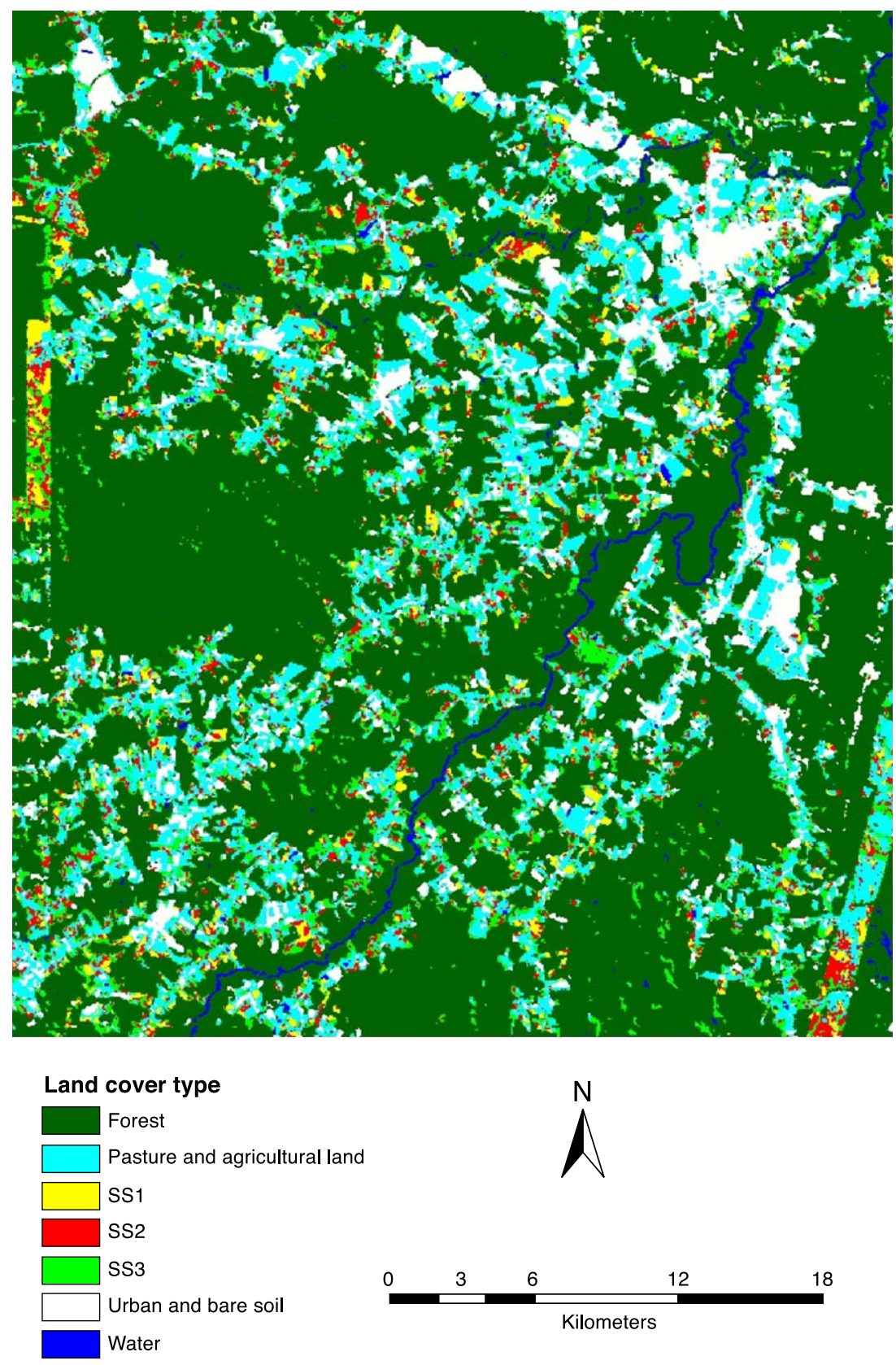

Fig. 6. Land-cover distribution using the threshold method on shade-GV ratio image.

soil fraction. These non-forested areas were masked out from GV and shade fraction images. Thus only successional and mature forests remained on the GV and shade fraction images for further classification. The threshold ranges for each successional and mature forest class were defined based on the integration of field sample sets and fraction images as previously indicated. The classified image indicated that mature forest accounted for most of the study area. Different successional forests, agricultural lands, and pastures were distributed along both sides of roads.

The accuracy assessment for each classified image was conducted based on the test data from field work and IKONOS data. The error matrix was created for each classification method through the comparison of test data and the classified image. Table 1 provides the error matrix, from the thresholding method based on shade-to-GV ratio images. Approximately $78.2 \%$ of overall accuracy was obtained. Mature forest had the highest classification accuracy, with $98.5 \%$ of PA and $95.6 \%$ of UA. SS3 had the lowest accuracy, with only $57.9 \%$ of PA and UA.

Table 2 shows the comparison of accuracy between different analysis methods. The methods used were (1) thresholding based on ratio of shade-to-GV fraction images; (2) thresholding based on GV and shade fraction images; (3) MLC on atmospherically corrected TM image; and (4) MLC on shade and GV fractions. Table 2 indicates that the LMM 
Table 1

An error matrix for the classified image derived from the threshold of shade-GV ratio image

\begin{tabular}{lccccccc}
\hline Classified data & \multicolumn{7}{l}{ Reference data } \\
\cline { 2 - 8 } & SS1 & SS2 & SS3 & MF & Other & Row total & UA\% \\
\hline SS1 & 21 & 10 & 1 & 0 & 6 & 38 & 55.26 \\
SS2 & 6 & 23 & 4 & 0 & 3 & 36 & 63.89 \\
SS3 & 1 & 4 & 11 & 1 & 2 & 19 & 57.89 \\
MF & 0 & 0 & 3 & 65 & 0 & 68 & 95.59 \\
Other & 2 & 1 & 0 & 0 & 38 & 41 & 92.68 \\
Column total & 30 & 38 & 19 & 66 & 49 & 202 & \\
PA\% & 70.00 & 60.53 & 57.89 & 98.48 & 77.55 & & \\
\hline
\end{tabular}

$\mathrm{UA}=$ user's accuracy; $\mathrm{PA}=$ producer's accuracy; Other includes pasture, agricultural land, urban areas, bare soils, and water.

approach achieved accuracies approximately $5.9-7.4 \%$ higher than the MLC (76.7-78.2\% for LMM approaches vs. $70.8 \%$ for MLC approach). The shade-to-GV ratio image provided the highest overall accuracy, mainly through improved discrimination between successional stages-a particularly valuable contribution. The MLC on shade and GV fractions provided similar classification accuracies as the threshold methods. The KHAT statistic of each classification method also confirmed that the LMM approach provided better classification results than that using MLC on TM images.

Table 3 shows the kappa analysis results between the error matrices. It indicates that these methods were not significantly different at the $95 \%$ confidence level, but the thresholding method based on shade-to-GV ratio image was significantly better than the MLC on TM image at the $90 \%$ confidence level. Also the thresholding method and MLC based on the GV and shade images showed significantly better performance than MLC on TM image at the $80 \%$ confidence level. The results imply that LMM is an effective analysis tool that improved the separability of different successional stages and mature forest in the Amazon basin.

As previously indicated, the LMM approach provides fractions with biophysical meaning. The fraction value derived from the LMM approach represents areal proportion of each endmember in a pixel. Different successional stages have their own stand structure features, thus leading to
Table 3

Comparison of kappa analysis results between error matrices

\begin{tabular}{lrlll}
\hline Comparison & Z-Statistic & \multicolumn{2}{l}{ Confidence level (\%) } \\
\cline { 3 - 5 } & & 95 & 90 & 80 \\
\hline (1) vs. (2) & 0.3866 & $\mathrm{NS}$ & $\mathrm{NS}$ & $\mathrm{NS}$ \\
(1) vs. (3) & 1.7974 & $\mathrm{NS}$ & $\mathrm{S}$ & $\mathrm{S}$ \\
(1) vs. (4) & 0.2674 & $\mathrm{NS}$ & $\mathrm{NS}$ & $\mathrm{NS}$ \\
(2) vs. (3) & 1.4100 & $\mathrm{NS}$ & $\mathrm{NS}$ & $\mathrm{S}$ \\
(2) vs. (4) & -0.1192 & $\mathrm{NS}$ & $\mathrm{NS}$ & $\mathrm{NS}$ \\
(3) vs. (4) & -1.5292 & $\mathrm{NS}$ & $\mathrm{NS}$ & $\mathrm{S}$ \\
\hline
\end{tabular}

(1) Thresholding on shade-GV ratio image; (2) Thresholding on GV and shade fraction images; (3) MLC on atmospherically corrected TM image; (4) MLC on GV and shade fraction images; S-Significant difference; NS-No significant difference.

different proportional composition of endmembers. In SS1, grassy vegetation and pioneer species dominate the majority of above-ground biomass. In this stage, dense ground structure with lack of stratification and a structured canopy of trees results in high GV but low shade fraction values. In SS2, although young trees appear, the saplings account for most of the above-ground biomass. The vegetation stand in this stage lacks obvious stratification. This characteristic is reflected on GV and shade fractions with fraction values similar to those of SS1. In SS3, trees occupy the canopy with obvious stratification of multilayer structures. This feature results in significantly reduced GV fraction but increased shade fraction compared with SS1 and SS2. In mature forest, the majority of the biomass is in woody vegetation. A well-stratified and well-structured vegetation stand is formed. This makes the GV fraction lower still but the shade fraction is higher than in SS3. The GV and shade fractions are more closely related to the vegetation stand structures, especially the vertical structure and canopy geometry of vegetation stands. As vegetation grows from SS1 to SS3 and mature forest, shade content increases because canopies become more heterogeneous with increasing numbers of gaps and emergents. The presence of gaps and emergents accounts for increasing shade. These relationships between vegetation stand features and fractions imply that GV fraction is more correlated with leaf area indices and shade fraction is more correlated with

Table 2

Comparison of accuracy analysis results among different classification methods

\begin{tabular}{|c|c|c|c|c|c|c|c|c|}
\hline \multirow[t]{2}{*}{ Classified classes } & \multicolumn{2}{|c|}{$\begin{array}{l}\text { Thresholding on shade-GV } \\
\text { ratio image }\end{array}$} & \multicolumn{2}{|c|}{$\begin{array}{l}\text { Thresholding on GV and } \\
\text { shade image }\end{array}$} & \multicolumn{2}{|c|}{ MLC on TM image } & \multicolumn{2}{|c|}{$\begin{array}{l}\text { MLC on GV and } \\
\text { shade image }\end{array}$} \\
\hline & UA $\%$ & $\mathrm{PA} \%$ & UA $\%$ & $\mathrm{PA} \%$ & UA $\%$ & $\mathrm{PA} \%$ & UA\% & $\mathrm{PA} \%$ \\
\hline SS1 & 55.26 & 70.00 & 50.00 & 63.33 & 44.74 & 51.52 & 50.00 & 63.33 \\
\hline SS2 & 63.89 & 60.53 & 63.89 & 57.50 & 61.11 & 56.41 & 63.89 & 57.50 \\
\hline SS3 & 57.89 & 57.89 & 52.63 & 62.50 & 42.11 & 53.33 & 52.63 & 66.67 \\
\hline Forest & 95.59 & 98.48 & 97.06 & 98.51 & 92.65 & 98.44 & 97.06 & 98.51 \\
\hline Other & 92.68 & 77.55 & 90.24 & 75.51 & 80.49 & 64.71 & 92.68 & 76.00 \\
\hline $\mathrm{OA} \%$ & \multicolumn{2}{|l|}{78.22} & \multicolumn{2}{|l|}{76.73} & \multicolumn{2}{|l|}{70.79} & \multicolumn{2}{|l|}{77.23} \\
\hline KHAT Statistic & \multicolumn{2}{|l|}{0.7173} & \multicolumn{2}{|l|}{0.6972} & \multicolumn{2}{|c|}{0.6207} & \multicolumn{2}{|c|}{0.7034} \\
\hline KAPPA Variance & \multicolumn{2}{|l|}{0.00131957} & \multicolumn{2}{|l|}{0.00137711} & \multicolumn{2}{|c|}{0.00157017} & \multicolumn{2}{|c|}{0.00136019} \\
\hline
\end{tabular}

$\mathrm{UA}=$ user's accuracy; $\mathrm{PA}=$ producer's accuracy; $\mathrm{OA}=$ overall accuracy. 
canopy geometry and stratification, especially in advanced SS and mature forests.

Different successional forests have their own composition of GV and shade fractions. If multitemporal or multiscene TM data used in a specific project with similar landscape and environmental conditions are radiometrically and atmospherically calibrated, the LMM approach can provide stable fraction results. Thus the threshold methods based on the LMM fraction images can be extrapolated to different dates of TM images for change detection or for classification of land covers in a large area. Some previous research has shown that the LMM is a promising approach for land-cover classification and change detection in the moist tropical region (Adams et al., 1995; Roberts et al., 1998, 2002). Caution must be taken when the multitemporal TM data have different sun elevation angles, especially in a rugged region. In this case, accurate topographic correction using digital elevation model (DEM) data may be necessary.

Earlier work on SS classification based on field measurements indicated that some biophysical parameters (e.g., average stand height, biomass, ratio of sapling to tree basal area, and RTB) are sensitive to the change of SS stages (Lu, 2001; Moran \& Brondízio, 1998; Tucker et al., 1998). Meanwhile, soil fertility, topography, land-use history, and original vegetation influence the rate of vegetation regrowth (Lu, Moran, \& Mausel, 2002; Moran et al., 2000). Vegetation stand structures, vegetation vigor, species composition, and soil conditions affect the reflectance values captured by remote sensing sensors. Because of the complexity of biophysical environments on SS stages, remote-sensing signatures cannot effectively reflect the difference between SS ages. This makes classification difficult in subclasses of succession. However, the GV and shade fractions that were developed using the LMM approach provided better relationships with biophysical parameters of SS stages. This implies a potential to improve the separability between the SS stages as indicated in Fig. 4 and in Tables 2 and 3. Also, $\mathrm{GV}$ fraction is increasing but shade fraction is decreasing as successional stand structure changes from SS1 to SS3 and to mature forest, so the ratio of shade-to-GV fractions provides a way to enhance the difference between SS stages and improve the classification accuracy. On the other hand, it is much easier to define the optimal thresholds for each successional class on the ratio image than on the GV and shade fraction images.

Although the LMM approach provided better results than MLC, the classification accuracies of successional forests are still unsatisfactory. The main reason is that no clear boundary exists between the successional stages. For example, some SS1 vegetation has similar stand structure with SS2. Also some degraded pastures and coffee plantations are confused with successional forests, reducing the classification accuracy. Previous study also indicates that classification of tropical SS vegetation purely based on spectral signature is often unsuccessful. Spectral-spatial-based classifiers were confirmed to provide better results than other per-pixel classifiers (Brondízio et al., 1996; Mausel et al., 1993; Moran, Brondízio, \& Mausel, 1994). However, due to the limitation of radiometric and spectral resolutions, it is difficult to greatly improve the SS classification accuracy. In terms of the availability of new sensors and data, optical and microwave data provide complementary information about land cover and forest fragmentation. Besides overcoming the problem of cloud cover, use of radar data or integration of radar data with multispectral data is a promising way for future land-cover mapping of the Amazon (Rignot et al., 1997; Saatchi et al., 1997; Yanasse et al., 1997). Hyperspectral data, such as produced by the Airborne Visible/ Infrared Imaging Spectrometer (AVIRIS) has the potential to provide the means to achieve better classification of SS stages. An alternative to improve the extraction of Earth surface feature information for vegetation classifications in the Amazon is the use of state-of-the-art techniques for image processing and classification. Among others, spectral mixture analysis (Adams et al., 1995; Roberts et al., 1998), spatial-spectral classifiers (Foody et al., 1996), spectral indices of canopy brightness (Steininger, 1996) and GISinformed classifications (Hinton, 1996; Batistella et al., 2000) are among the main trends to improve monitoring of SS.

\section{Conclusion}

In the Amazon basin, mixed pixels in Landsat TM images are common because of the complex vegetation stand structure, abundant vegetation species, and the limitations of spatial resolution from remotely sensed data in such a heterogeneous environment. Without extensive field data collection, previous research on successional and mature forest classification using per-pixel classifiers such as the MLC has not provided satisfactory classification results of secondary succession because a per-pixel classifier cannot handle mixed pixels. In this research, a constrained linear mixture model approach was used to classify successional and mature forests in Rondônia, Brazilian Amazon. This research indicates that the linear mixture model approach is a promising method in discriminating secondary succession and mature forest. An overall accuracy of 78.2\% was achieved, which represents an accuracy increase of about $7.4 \%$ compared to the MLC. The shade and GV fractions are particularly suitable to discriminate successional and mature forests, because they provide biophysical structural information. As vegetation grows, the GV fraction decreases and the shade fraction increases. Using a ratio of shade-to-GV fraction slightly improved the discrimination among vegetation classes, and classification using the MLC on GV and shade fraction images provided accuracy similar to that of threshold methods. This indicates that GV and shade fraction images developed using the linear mixture model approach provided a better separability between successional and mature forests. 


\section{Acknowledgements}

The authors wish to thank the National Science Foundation (grants 95-21918 and 99-06826), the National Aeronautics and Space Administration (grant N005-334), and Brazil's CAPES (Program for the Advancement of Education) for their support, which provided funds for the research that led to this paper. This project is part of the Large-Scale Biosphere-Atmosphere Experiment in Amazônia (LBA) program, LC-09, examining the human and physical dimensions of land-use and land-cover change. We also thank Indiana State University and Indiana University for facilities and support of our work and collaborators in Brazil, especially the LBA Program, EMBRAPA, INPE, and the population of the study area, who made this work possible. The authors wish to thank the journal reviewers for their constructive suggestions. None of the funding organizations or individuals mentioned above should be held responsible for the views presented in this paper.

\section{References}

Adams, J. B., Sabol, D. E., Kapos, V., Filho, R. A., Roberts, D. A., Smith, M. O., \& Gillespie, A. R. (1995). Classification of multispectral images based on fractions of endmembers: Application to land-cover change in the Brazilian Amazon. Remote Sensing of Environment, 52, 137-154.

Adams, J. B., Smith, M. O., \& Gillespie, A. R. (1993). Imaging spectroscopy: Interpretation based on spectral mixture analysis. In C. M. Englert, \& P. A. J. Englert (Eds.), Remote geochemical analysis. Topics in Remote Sensing, vol. 4 (pp. 145-166). Cambridge, UK: Cambridge University Press.

Aguiar, A. P. D., Shimabukuro, Y. E., \& Mascarenhas, N. D. A. (1999) Use of synthetic bands derived from mixture models in the multispectral classification of remote sensing images. International Journal of Remote Sensing, 20, 647-657.

Alves, D., Soares, J. V., Amaral, S., Mello, E. K., Almeida, S. A. S., de Silva, O. F., \& Silveira, A. M. (1997). Biomass of primary and secondary vegetation in Rondônia, Western Brazilian Amazon. Global Change Biology, 3, 451-461.

Asner, G. P., \& Lobell, D. B. (2000). A biogeophysical approach for automated SWIR unmixture of soils and vegetation. Remote Sensing of Environment, 74, 99-112.

Atkinson, P. M., Cutler, M. E. J., \& Lewts, H. (1997). Mapping subpixel proportional land cover with AVHRR imagery. International Journal of Remote Sensing, 18, 917-935.

Bastin, L. (1997). Comparison of fuzzy c-means classification, linear mixture modeling and MLC probabilities as tools for unmixing coarse pixels. International Journal of Remote Sensing, 18, 3629-3648.

Bateson, A., \& Curtiss, B. (1996). A method for manual endmember selection and spectral unmixing. Remote Sensing of Environment, 55, 229-243.

Batistella, M. (2001). Landscape change and land-use/land-cover dynamics in Rondônia, Brazilian Amazon. PhD diss., Indiana University, Bloomington: Indiana, $399 \mathrm{pp}$

Batistella, M., Brondízio, E. S., \& Moran, E. F. (2000). Comparative analysis of landscape fragmentation in Rondônia, Brazilian Amazon. IAPRS, Vol. XXXIII, proceedings. Amsterdam, The Netherlands: International Society for Photogrammetry and Remote Sensing (CD ROM).

Batistella, M., \& de Castro, F. (2001). Institutional design and landscape fragmentation: A comparative study of rural colonization projects in the Brazilian Amazon. The 16th Annual Symposium of the U.S. Chapter of
International Association of Landscape Ecology (US-IALE), Abstracts. Tempe, AZ: IALE.

Boardman, J. M. (1993). Automated spectral unmixing of AVIRIS data using convex geometry concepts. Summaries of the Fourth JPL Airborne Geoscience Workshop. JPL Publication, vol. 93-26 (pp. 11-14).

Boardman, J. M., Kruse, F. A., \& Green, R. O. (1995). Mapping target signature via partial unmixing of AVIRIS data. Summaries of the Fifth JPL Airborne Earth Science Workshop. JPL Publication, vol. 95-1 (pp. 23-26).

Brondízio, E. S., Moran, E. F., Mausel, P., \& Wu, Y. (1994). Land use change in the Amazon estuary: Patterns of Caboclo settlement and landscape management. Human Ecology, 22, 249-278.

Brondízio, E. S., Moran, E. F., Mausel, P., \& Wu, Y. (1996). Land cover in the Amazon estuary: Linking of the Thematic Mapper with botanical and historical data. Photogrammetric Engineering and Remote Sensing, $62,921-929$

Campbell, J. B. (1996). Introduction to remote sensing (2nd ed.). New York: Guilford Press.

Chavez Jr., P. S. (1996). Image-based atmospheric corrections-revisited and improved. Photogrammetric Engineering and Remote Sensing, 62, $1025-1036$.

CIPEC (Center for the Study of Institutions, Population, and Environmental Change) (1998). International Forestry Resources and Institutions (IFRI) Research Program, Field Manual. Bloomington, CIPEC, Indiana University.

Cochrane, M. A., \& Souza Jr., C. M. (1998). Linear mixture model classification of burned forests in the eastern Amazon. International Journal of Remote Sensing, 19, 3433-3440.

Congalton, R. G. (1991). A review of assessing the accuracy of classification of remotely sensed data. Remote Sensing of Environment, 37, 35-46.

Congalton, R. G., \& Mead, R. A. (1983). A quantitative method to test for consistency and correctness in photo interpretation. Photogrammetric Engineering and Remote Sensing, 49, 69-74.

Congalton, R. G., Oderwald, R. G., \& Mead, R. A. (1983). Assessing Landsat classification accuracy using discrete multivariate analysis statistical techniques. Photogrammetric Engineering and Remote Sensing, 49, 1671-1678.

DeFries, R. S., Hansen, M. C., \& Townshend, J. R. G. (2000). Global continuous fields of vegetation characteristics: A linear mixture model applied to multi-year $8 \mathrm{~km}$ AVHRR data. International Journal of Remote Sensing, 21, 1389-1414.

Elmore, A. J., Mustard, J. F., Manning, S. J., \& Lobell, D. B. (2000). Quantifying vegetation change in semiarid environments: Precision and accuracy of spectral mixture analysis and the normalized difference vegetation index. Remote Sensing of Environment, 73, 87-102.

Erol, H. (2000). A practical method for constructing the mixture model for a spectral class. International Journal of Remote Sensing, 21, 823-830.

Foody, G. M., \& Curran, P. J. (1994). Estimation of tropical forest extent and regenerative stage using remotely sensed data. Journal of Biogeography, 21, 223-244.

Foody, G. M., Palubinskas, G., Lucas, R. M., Curran, P. J., \& Honzák, M. (1996). Identifying terrestrial carbon sinks: Classification of successional stages in regenerating tropical forest from Landsat TM data. Remote Sensing of Environment, 55, 205-216.

Garcia-Haro, F. J., Gilabert, M. A., \& Melia, J. (1996). Linear spectral mixture modeling to estimate vegetation amount from optical spectral data. International Journal of Remote Sensing, 17, 3373-3400.

Gilabert, M. A., Garcia-Haro, F. J., \& Melia, J. (2000). A mixture modeling approach to estimate vegetation parameters for heterogeneous canopies in remote sensing. Remote Sensing of Environment, 72, 328-345.

Gómez-Pompa, A., \& Vásquez-Yanes, C. (1981). Successional studies of a rain forest in Mexico. In D. C. West, H. H. Shugart, \& D. B. Botkin (Eds.), Forest succession, concepts and application (pp. 246-266). New York: Springer-Verlag.

Guariguata, M. R., \& Ostertag, R. (2001). Neotropical secondary forest succession: Change in structural and functional characteristics. Forest Ecology and Management, 148, 185-206. 
Hall, F. G., Shimabukuro, Y. E., \& Huemmrich, K. F. (1995). Remote sensing of forest biophysical structure using mixture decomposition and geometric reflectance models. Ecological Applications, 5, 993-1013.

Hinton, J. C. (1996). GIS and remote sensing integration for environmental applications. International Journal of Geographical Information Systems, 10, 877-890.

Hudson, W. D., \& Ramm, C. W. (1987). Correct formulation of the Kappa coefficient of agreement. Photogrammetric Engineering and Remote Sensing, 53, 421-422.

Huguenin, R. L., Karaska, M. A., Blaricom, D. V., \& Jensen, J. R. (1997). Subpixel classification of Bald Cypress and Tupelo Gum trees in Thematic Mapper imagery. Photogrammetric Engineering and Remote Sensing, 63, 717-725.

Ichoku, C., \& Karnieli, A. (1996). A review of mixture modeling techniques for sub-pixel land cover estimation. Remote Sensing Reviews, 13, $161-186$.

Instituto Nacional de Pesquisas Espaciais (INPE) (2002). Monitoring of the Brazilian Amazon forest by satellite 2000-2001. Brazil: INPE.

Janssen, L. F. J., \& van der Wel, F. J. M. (1994). Accuracy assessment of satellite derived land-cover data: A review. Photogrammetric Engineering and Remote Sensing, 60, 419-426.

Jensen, J. R. (1996). Introduction digital image processing: A remote sensing perspective (2nd ed.). New York: Prentice Hall.

Kalkhan, M. A., Reich, R. M., \& Czaplewski, R. L. (1997). Variance estimates and confidence intervals for the Kappa measure of classification accuracy. Canadian Journal of Remote Sensing, 23, 210-216.

Khorram, S. (Ed.) (1999). Accuracy assessment of remote sensing-derived change detection. Monograph series. Bethesda, MD: American Society for Photogrammetry and Remote Sensing.

Kimes, D. S., Nelson, R. F., Salas, W. A., \& Skole, D. L. (1999). Mapping secondary tropical forest and forest age from SPOT HRV data. International Journal of Remote Sensing, 20, 3625-3640.

Kimes, D. S., Nelson, R. F., Skole, D. L., \& Salas, W. A. (1999). Accuracies in mapping secondary tropical forest age from sequential satellite imagery. Remote Sensing of Environment, 65, 112-120.

Li, Y., Moran, E. F., Brondízio, E. S., Mausel, P., \& Wu, Y. (1994, February). Discrimination between advanced secondary succession and mature moist forest near Altamira, Brazil using Landsat TM data. Proceedings of the American Society for Photogrammetry and Remote Sensing 1994 Annual Meeting, Reno, Nev. Bethesda, MD: American Society for Photogrammetry and Remote Sensing.

$\mathrm{Lu}$, D. (2001). Estimation of forest stand parameters and application in classification and change detection of forest cover types in the Brazilian Amazon basin. PhD diss., Indiana State University, Terre Haute, IN, USA.

Lu, D., Mausel, P., Brondízio, E. S., \& Moran, E. (2002a). Assessment of atmospheric correction methods for Landsat TM data applicable to Amazon basin LBA research. International Journal of Remote Sensing, 23, 2651-2671.

Lu, D., Mausel, P., Brondízio, E. S., \& Moran, E. (2002b). Change detection of successional and mature forests based on forest stand characteristics using multitemporal TM data in Altamira, Brazil. ACSM-ASPRS 2002 Annual Conference Proceedings, Washington, DC, CD ROM.

Lu, D., Moran, E., \& Mausel, P. (2002). Linking Amazonian secondary succession forest growth to soil properties. Land Degradation and Development, 13, 331-343.

Lucas, R. M., Curran, P. J., Honzák, M., Foody, G. M., do Amaral, I., \& Amaral, S. (1998). The contribution of remotely sensed data in the assessment of the floristic composition, total biomass and structure of Amazonian tropical secondary forests. In C. Gascon, \& P. Moutinho (Eds.), Regeneraçaõ Florestal: Pesquisas na Amazonia (pp. 61-82). Manaus: INPA Press.

Lucas, R. M., Honzák, M., Curran, P. J., Foody, G. M., Mline, R., Brown, T., \& Amaral, S. (2000). The regeneration of tropical forests within the Legal Amazon. International Journal of Remote Sensing, $21,2855-2881$.
Lucas, R. M., Honzák, M., do Amaral, S., Curran, P. J., \& Foody, G. M. (2002). Forest regeneration on abandoned clearance in central Amazonia. International Journal of Remote Sensing, 23, 965-988.

Lucas, R. M., Honzák, M., Foody, G. M., Curran, P. J., \& Corves, C. (1993). Characterizing tropical secondary forests using multitemporal Landsat sensor imagery. International Journal of Remote Sensing, 14, 3061-3067.

Maas, S. J. (2000). Linear mixture modeling approach for estimating cotton canopy ground cover using satellite multispectral imagery. Remote Sensing of Environment, 72, 304-308.

Mather, P. M. (1999). Computer processing of remotely-sensed images: An introduction (2nd ed.). New York: Wiley.

Mausel, P., Wu, Y., Li, Y., Moran, E. F., \& Brondízio, E. S. (1993). Spectral identification of succession stages following deforestation in the Amazon. Geocarto International, 8, 61-72.

McCracken, S., Brondízio, E., Nelson, D., Moran, E., Siqueira, A., \& Rodriguez-Pedraza, C. (1999). Remote sensing and GIS at farm property level: Demography and deforestation in the Brazilian Amazon. Photogrammetric Engineering and Remote Sensing, 65, 1311-1320.

McGwire, K., Minor, T., \& Fenstermaker, L. (2000). Hyperspectral mixture modeling for quantifying sparse vegetation cover in arid environments. Remote Sensing of Environment, 72, 360-374.

Miranda, E. E., \& Mattos, C. (1993). Machadinho d'Oeste: De colonos a munícipes na floresta tropical de Rondônia. Campinas, Brasil: Ecoforça/ EMBRAPA-NMA.

Moran, E. F. (1981). Developing the Amazon. Bloomington, IN: Indiana University Press.

Moran, E. F., \& Brondízio, E. S. (1998). Land-use change after deforestation in Amazônia. In D. Liverman, E. F. Moran, R. R. Rindfuss, \& P. C. Stern (Eds.), People and pixels: Linking remote sensing and social science (pp. 94-120). Washington, DC: National Academy Press.

Moran, E. F., Brondízio, E. S., \& Mausel, P. (1994). Secondary succession. Research and Exploration, 10, 458-476.

Moran, E. F., Brondízio, E. S., Mausel, P., \& Wu, Y. (1994). Integrating Amazonian vegetation, land use and satellite data. BioScience, 44, $329-338$.

Moran, E. F., Brondízio, E. S., Tucker, J. M., da Silva-Forsberg, M. C., McCracken, S. D., \& Falesi, I. (2000). Effects of soil fertility and land use on forest succession in Amazônia. Forest Ecology and Management, 139, 93-108.

Mustard, J. F., \& Sunshine, J. M. (1999). Spectral analysis for Earth science: Investigations using remote sensing data. In A. N. Rencz (Ed.), Remote Sensing for the Earth Sciences: Manual of Remote Sensing, vol. 3 (3rd ed.) (pp. 251-307). New York: Wiley.

Nelson, B. W., Mesquita, R., Pereira, J. L. G., de Souza, S. G. A., Batista, G. T., \& Couto, L. B. (1999). Allometric regression for improved estimate of secondary forest biomass in the central Amazon. Forest Ecology and Management, 117, 149-167.

Nelson, R. F., Kimes, D. S., Salas, W. A., \& Routhier, M. (2000). Secondary forest age and tropical forest biomass estimation using Thematic Mapper imagery. Bioscience, 50, 419-431.

Novo, E. M., \& Shimabukuro, Y. E. (1997). Identification and mapping of the Amazon habitats using a mixing model. International Journal of Remote Sensing, 18, 663-670.

Peddle, D. R., Brunke, S. P., \& Hall, F. G. (2001). A comparison of spectral mixture analysis and ten vegetation indices for estimating boreal forest biophysical information from airborne data. Canadian Journal of Remote Sensing, 27, 627-635.

Peddle, D. R., Hall, F. G., \& LeDrew, E. F. (1999). Spectral mixture analysis and geometric-optical reflectance modeling of boreal forest biophysical structure. Remote Sensing of Environment, 67, 288-297.

Quarmby, N. A., Townshend, J. R. G., Settle, J. J., \& White, K. H. (1992). Linear mixture modeling applied to AVHRR data for crop area estimation. International Journal of Remote Sensing, 13, 415-425.

Research Systems (RSI) (2000). ENVI user's guide. Boulder, CO: Research Systems. 
Rignot, E., Salas, W. A., \& Skole, D. L. (1997). Mapping deforestation and secondary growth in Rondônia, Brazil, using imaging radar and Thematic Mapper data. Remote Sensing of Environment, 59, $167-179$.

Roberts, D. A., Batista, G. T., Pereira, J. L. G., Waller, E. K., \& Nelson, B. W. (1998). Change identification using multitemporal spectral mixture analysis: Applications in eastern Amazônia. In R. S. Lunetta, \& C. D. Elvidge (Eds.), Remote sensing change detection: Environmental monitoring methods and applications (pp. 137-161). Ann Arbor, MI: Ann Arbor Press.

Roberts, D. A., Green, R. O., \& Adams, J. B. (1997). Temporal and spatial patterns in vegetation and atmospheric properties from AVIRIS. Remote Sensing of Environment, 62, 223-240.

Roberts, D. A., Numata, I., Holmes, K., Batista, G., Krug, T., Monteiro, A., Powell, B., \& Chadwick, O. A. (2002). Large area mapping of landcover change in Rondonia using decision tree classifiers. Journal of Geophysical Research, 107(D20), 8073 (LBA 40-1 to 40-18) .

Roberts, D. A., Smith, M. O., \& Adams, J. B. (1993). Green vegetation, non-photosynthetic vegetation, and soils in AVIRIS data. Remote Sensing of Environment, 44, 255-269.

Rogan, J., Franklin, J., \& Roberts, D. A. (2002). A comparison of methods for monitoring multitemporal vegetation change using Thematic Mapper imagery. Remote Sensing of Environment, 80, 143-156.

Rondônia (1998). Diagnóstico sócio-econômico do Estado de Rondônia e assistência técnica para formulação da segunda aproximação do zoneamento sócio-econômico-ecológico-Climatologia, v.1. Governo de Rondônia/PLANAFLORO, Porto Velho, Brasil.

Saatchi, S. S., Soares, J. V., \& Alves, D. S. (1997). Mapping deforestation and land use in Amazon rainforest by using SIR-C imagery. Remote Sensing of Environment, 59, 191-202.

Saldarriaga, J. G., West, D. C., Tharp, M. L., \& Uhl, C. (1988). Long-term chronosequence of forest succession in the Upper Rio Negro of Colombia and Venezuela. Journal of Ecology, 76, 938-958.

Schmink, M., \& Wood, C. H. (1992). Contested frontiers in Amazônia. New York: Columbia University Press.

Settle, J. J., \& Drake, N. A. (1993). Linear mixing and the estimation of ground cover proportions. International Journal of Remote Sensing, 14, $1159-1177$.

Shimabukuro, Y. E., Batista, G. T., Melio, E. M. K., Moreira, J. C., \& Duarte, V. (1998). Using shade fraction image segmentation to evaluate deforestation in Landsat Thematic Mapper images of the Amazon region. International Journal of Remote Sensing, 19, 535-541.

Shimabukuro, Y. E., \& Smith, J. A. (1995). Fraction images derived from Landsat TM and MSS data for monitoring reforested areas. Canadian Journal of Remote Sensing, 21, 67-74.

Shuttleworth, W. J. (1998). Evaporation from Amazonian rain forest. Proceedings of Royal Society of London, Série B, 233, 321-346.

Small, C. (2001). Estimation of urban vegetation abundance by spectral mixture analysis. International Journal of Remote Sensing, 22, $1305-1334$

Smith, M. O., Ustin, S. L., Adams, J. B., \& Gillespie, A. R. (1990).
Vegetation in deserts: I. A regional measure of abundance from multispectral images. Remote Sensing of Environment, 31, 1-26.

Smith, J., van de Kop, P., Reategui, K., Lombardi, I., Sabogal, C., \& Diaz, A. (1997). Can secondary forests compensate for primary forest destruction? Implications from small-scale farms in the Peruvian Amazon. Working paper. Bogor, Indonesia: Center for International Forestry Research.

Smits, P. C., Dellepiane, S. G., \& Schowengerdt, R. A. (1999). Quality assessment of image classification algorithms for land-cover mapping: A review and a proposal for a cost-based approach. International Journal of Remote Sensing, 20, 1461-1486.

Sohn, Y., \& McCoy, R. M. (1997). Mapping desert shrub rangeland using spectral unmixture and modeling spectral mixtures with TM data. Photogrammetric Engineering and Remote Sensing, 63, 707-716.

Steininger, M. K. (1996). Tropical secondary forest regrowth in the Amazon: Age, area and change estimation with Thematic Mapper data. International Journal of Remote Sensing, 17, 9-27.

Theseira, M. A., Thomas, G., \& Sannier, C. A. D. (2002). An evaluation of spectral mixture modeling applied to a semi-arid environment. International Journal of Remote Sensing, 23, 687-700.

Tompkins, S., Mustard, J. F., Pieters, C. M., \& Forsyth, D. W. (1997). Optimization of endmembers for spectral mixture analysis. Remote Sensing of Environment, 59, 472-489.

Tucker, J. M., Brondízio, E. S., \& Moran, E. F. (1998). Rates of forest regrowth in Eastern Amazônia: A comparison of Altamira and Bragantina regions, Para State, Brazil. Interciencia, 23, 64-73.

Uhl, C., Buschbacher, R., \& Serrao, E. A. S. (1988). Abandoned pastures in eastern Amazônia: I. Patterns of plant succession. Journal of Ecology, $76,663-681$

Ustin, S. L., Hart, Q. J., Duan, L., \& Scheer, G. (1996). Vegetation mapping on hardwood rangelands in California. International Journal of Remote Sensing, 17, 3015-3036.

Ustin, S. L., Roberts, D. A., \& Hart, Q. J. (1998). Seasonal vegetation patterns in a California coastal savanna derived from Advanced Visible/Infrared Imaging Spectrometer (AVIRIS) data. In R. S. Lunetta, \& C. D. Elvidge (Eds.), Remote sensing change detection: Environmental monitoring methods and applications (pp. 163-180). Ann Arbor, MI: Ann Arbor Press.

Ustin, S. L., Smith, M. O., \& Adams, J. B. (1993). Remote sensing of ecological process: A strategy for developing and testing ecological models using spectral mixing analysis. In J. Ehleringer, \& C. Field (Eds.), Scaling physiological process: Leaf to globe (pp. 339-357). San Diego, CA: Academic Press.

Ustin, S. L., Smith, M. O., Jacquemoud, S., Verstraete, M., \& Govaerts, Y. (1999). Geobotany: Vegetation mapping for Earth sciences. In A. N. Rencz (Ed.), Remote Sensing for the Earth Sciences: Manual of Remote Sensing, vol. 3 (3rd ed.) (pp. 189-233). New York: Wiley.

Yanasse, C. C. F., Sant'Anna, S. J. S., Frery, A. C., Rennó, C. D., Soares, J. V., \& Luckman, A. J. (1997). Exploratory study of the relationship between tropical forest regeneration stages and SIR-C L and C data. Remote Sensing of Environment, 59, 180-190. 